\title{
Quality of monitoring and evaluation of malaria control activities: tracking stock-outs and replenishment of supplies in Anambra state, Nigeria
}

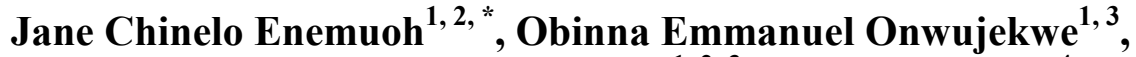 \\ Benjamin Sunday Chudi Uzochukwu ${ }^{1,2,3}$, Joseph Oranuba ${ }^{4}$, Amobi Linus Ilika ${ }^{5}$ \\ ${ }^{1}$ Department of Pharmacology and Therapeutics, College of Medicine, University of Nigeria, Enugu, Nigeria \\ ${ }^{2}$ Department of Community Medicine, College of Medicine, University of Nigeria, Enugu, Nigeria \\ ${ }^{3}$ Department of Health Administration and Management, College of Medicine, University of Nigeria, Enugu, Nigeria \\ ${ }^{4}$ Ministry of Health, Awka, Anambra State, Nigeria \\ ${ }^{5}$ Department of Community Medicine, Nnamdi Azikiwe University, Nnewi, Nigeria
}

\section{Email address:}

chinelo.enemuo@yahoo.com(J. C. Enemuoh),obinna.onwujekwe@unn.edu.ng (O. E. Onwujekwe), bscuzochukwu@gmail.com (B. S. C. Uzochukwu), linusilika@yahoo.com (A. L. Ilika), drjoeoranuba@yahoo.com (J. Oranuba)

\section{To cite this article:}

Jane Chinelo Enemuoh, Obinna Emmanuel Onwujekwe, Benjamin Sunday Chudi Uzochukwu, Joseph Oranuba, Amobi Linus Ilika. Quality of Monitoring and Evaluation of Malaria Control Activities: Tracking Stock-Outs and Replenishment of Supplies in Anambra State, Nigeria. Science Journal of Public Health. Vol. 1, No. 5, 2013, pp. 201-208. doi: 10.11648/j.sjph.20130105.13

\begin{abstract}
Introduction: The use of monitoring and evaluation (M\&E) data is recognized as a major factor in the improvement and strengthening of malaria control programmes. This study assesses the quality of M\&E in malaria control, with special emphasis on use of M\&E to detect and control stock-outs of drugs and other supplies. Methods:The study was undertaken in Anambra state, southeat Nigeria. Training on M\&E was used to improve health workers practice on the use of M\&E tools for malaria control. Data was collected from 210 health workers in the surveyed public health facilities using questionnaire to monitor and evaluate health workers knowledge and practice on the use of M\&E tools as well as on control for tracking stock-outs. Data on Observations were also collected on the completeness of the facilities' store records, commodity tracking systems and completed M\&E forms. Results: A total of 54(25.6\%) of the respondents had attended a training on the use of M\&E tools. Stock-out of malaria commodities was high, especially Artemisinin-based combination therapy (ACT). It took a long time for stock-outs to be reported to a higher level and replenished. The main reason for stock-outs was ineffective communication. In most cases, there were no feedbacks of data transmitted from lower to higher levels of the M\&E stratum. Conclusions: The quality of malaria M\&E is still sub-optimal leading to stock-out of malaria control commodities. Adequate strategies should be designed by programme managers so as to enhance more effective M\&E for improved malaria control.
\end{abstract}

Keywords: Malaria, Monitoring and Evaluation, Stock-out

\section{Introduction}

In order to scale up preventive and curative interventionto reduce the burden of malaria, some strategies were developed by the National malaria control programme in Nigeria[1] The key elements in these strategies are based on mortality control; case management and treatment using Artemisinin-based combination therapy (ACTs), diagnosing with microscopy and rapid diagnostic tests (RDTs), and environmental management through prevention with long lasting insecticide-treatednets (LLINs) and indoor residual spraying (IRS). There is also intermittent preventive treatment of malaria in pregnancy (IPTp) using Sulfadoxine-pyrimethanine.

In all of the interventions, Monitoring and evaluation (M\&E) is very critical as a support strategy [1-5] because managers need local-level information to effectively steer and guide their programmes to become responsive to local conditions [6]. M\&Ehas been one ofthemajor units in line with strategic intervention developedfor malaria control.[7]It measures output, outcomes and impact usingset out indictors for different activities [8]. These 
activities include procurement, distribution, availability, reporting and utilization of different interventions for control and treatment of malaria disease [7].

As countries scale-up coverage of key malaria interventions, sub-national monitoring is essential for resource allocation and priority setting [6,9]. Failure to monitor outcomes on these interventions on a regular basis at a decentralized level can hide programme inadequacies and inequities, delay necessary action to improve effectiveness and lead to missed opportunities to improve programmes [9].

Malaria M\&E provides regular data that guides planning, reprogramming and management of information within the health sector. Malaria information collection and collation are carried out using integrated disease surveillance response (IDSR), a routine monthly notification form. The data that are usually collected include: malaria incidence amongst children under five years, above five years, malaria in pregnancy, attending antenatal care, laboratory diagnosis, treatment given, outcome of treatment, whether patient was referred, reasons for referral, prevention strategy used and commodity tracking. These pieces of information reinforce the National Health Information Management System (NHIMS) and provide a platform for effective disease surveillance and control [7].

The health care facility level serves as the first level of contact and receives records from village/community bases health workers working within her locality.At this level, malaria data are collected daily on malaria morbidity and mortality, summarized monthly and sent to the LGA monitoring and evaluation unit .[10]Malaria data collected from public and private health facilities are aggregated at the state Ministry of Health (Epidemiology Unit)through local government area (LGA) M\&E office [7,11]. At the state (sub-national) level, monthly data collected at facility level are summarized and sent to the Federal Ministry of Health (Epidemiology and Planning Research and Statistics Unit) quarterly as well as reports on commodity tracking for national records and actions. [10] These data collected at both facility and state level are verified for correctness, completeness and accuracy on quarterly supervisory visits to health facilities and state malaria offices.

In Nigeria, M\&E in general constitutes of routine data collection and reportingon sets ofmalaria control indicators using monitoring and evaluation tools within the context of the National Health Management Information Systems (NHMIS).The M\&E tools in Nigeria include the Integrated Disease Surveillance and Response (IDRS) forms, Case fatality rate (CFR), I,II,III, procurement and supply management forms (PSM), Malaria indicator survey (MIS) tool, Demographic health survey (DHS) tool, Health facility surveys, population-basedsurveys etc. [7] Many of these M\&E tools have been used to monitor and evaluate malaria control activities. $[1,7]$

This paper provides new information on the quality of $M \& E$ on malaria control and its effect on tracking and replenishing stocks of malaria control commodities in the public sector in southeast. Nigeria. Only a few studies has been conducted on knowledge in Disease Surveillance and Notification (DSN) [10,12] but none has monitored or evaluated the impact of improved knowledge on malaria control. The paper therefore will contribute to research on $M \& E$ in malaria control in Nigeria and sub region to monitor progress in the delivery and utilization of intervention essential for scale up to sustain control and elimination of malaria disease.

\section{Main Body}

\subsection{Study Area}

The study was undertaken in Anambra State, southeast, Nigeria. The state has 21 Local Government Areas (LGA) with a population of 4,182,032 [13]. Across the 21 LGA in the state, 32 state owned secondary health facilities, 210 primary health care centers, 166 health care posts there are 430 hospitals which vary among health post, health centers and maternity and child health centers. [14 ]Indigenes of the state are predominately Igbo ethnicity with other tribes residing there. The occupation of majority of the population in the rural area includes trading, public service and government jobs while in the urban area, the main occupation for residents were mostly farming, palm wine tapping, and poultry rearing.

Malaria transmission occurs all year in the state but it is more prevalent during the rainy season, which is mostly from April to November. The malaria control interventions that have been implemented in the state in the 10 years include prevention using LLINS and IPTp, diagnosis of malaria cases with Rapid Diagnostic Testing (RDT) or microscopy, treatment of malaria cases using the two types of Artemisinin- based Combination Therapy (ACT); Artemeter Lumefantrine (AL) and Artesunate Amodiaquine (AA) in the different classes; ACT 1, ACT 2 and ACT3.

\subsection{Study Design and Sampling}

The study was a cluster randomized interventional study. In the cluster randomized trial segment, a baseline survey was conducted from May to June 2010 in health facilities. The study population consisted of heads of selected facilities, senior and junior health worker such as Senior Nurse Midwives, Senior Nurse Superintendent (SNS), Senior Community Health Extension Workers (S CHEW) and Junior Community Extension Workers (J CHEW). The different cadres of health workers and officers were selected to be trained on Monitoring and Evaluation (M\&E) of malaria control using an M\&E designed tool. The rationale for selecting these groups of health workers and officers are involved to day to day consultation with patients either for diagnosis or treatment of illnesses, reporting and replenishing stocks as the case maybe. They were also in charge of major decisions made in their respective facilities and offices. In Nigeria, $90 \%$ of heads of facilities are Senior Nurse Midwives, however, other 
cadres of health workers also benefited in the training through step down training down in the different facilities. To avoid contamination, health facilities training were stratified into 2 rounds of 5 clusters and in each round and the trainings were facilitated by 5 researchers who are malaria experts.(Figure 1 and Figure 2)

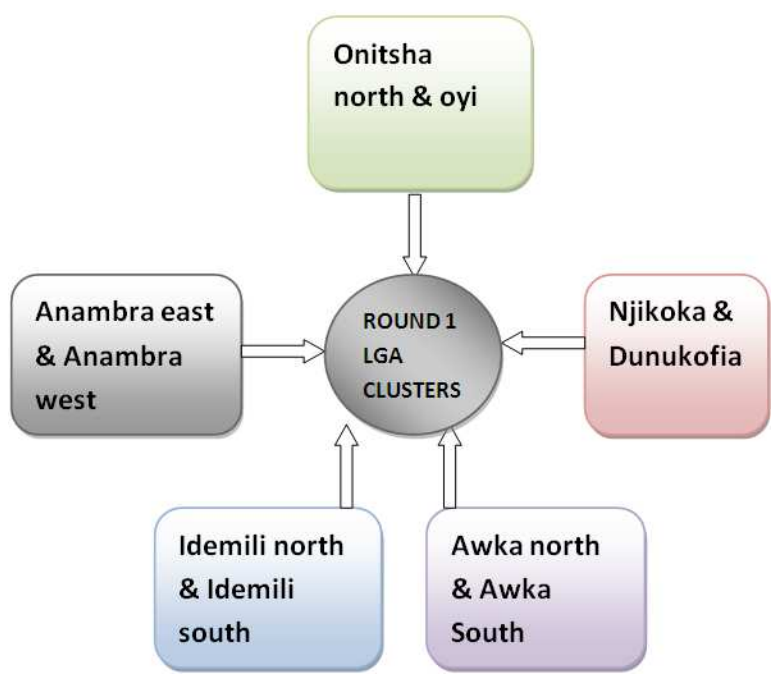

Figure 1. Round 1 clusters of 10 local government areas.

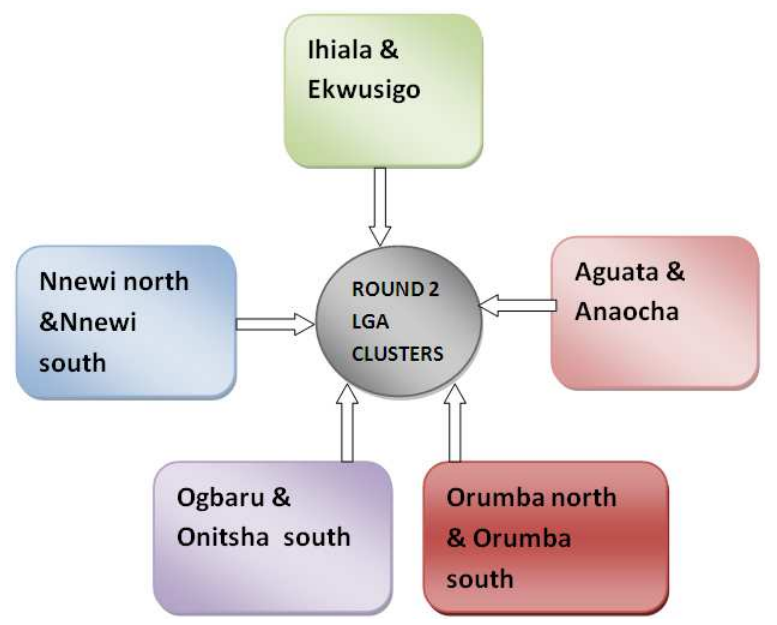

Figure 2. Round 2 clusters of 10 local government areas

\subsection{Intervention and Data Collection Procedures}

\subsubsection{Intervention}

This study was done in three components, the preparatory, intervention and evaluation components. After the baseline survey which was undertaken from May to June 2010, an intervention component was undertaken in August to September 2010. The intervention consisted of a tailored training of health workers and officers on the use of $\mathrm{M} \& \mathrm{E}$ tools for malaria control activities and the method of reporting and replenishing stock out of malaria control commodities. 2 state and 42 LGA officers and health workers were identified, trainedand used as trainer Of trainers (TOTs) about the use of M\&E tools and method of reporting and replenishing stock of malaria control commodities. The Trainer of Trainers gave training to all the selected health workers in the selected health facilities using manuals prepared in English Language and designed for the training. The different levels of trainings were supervised by researchers who are malaria experts from a University based research group and zonal malaria experts. Networks for information flow and appropriate duration were also established in the intervention LGAs and facilities to ensure sustainability. The network links the health facilities to LGA malaria control officer to the state malaria control offices to Federal Ministry of Health respectively (Figure 2).At the health facility level, researchers who are malaria experts and a focal person from malaria control team were assigned to monitor and supervise the training undertaken by trained state and LGA health workers. The investigators, malaria control team, researchers who are malaria experts and TOTs had regular weekly meetings to discuss progress of activities and challenges. The trainer of trainers reports their daily activities to Roll Back Malaria programme and researchers on a regular basis.

After the training, Monitoring and Evaluation (M\&E) tools in the form of daily health facility form, monthly health facility summary forms, and Local Government (LGA) summary forms were distributed to all selected health facilities and LGAs respectively.As of November 2010, all the LGAs andselected health facility has been visited by researchers who are malaria experts to check for the proper use ofM\&E forms, proper storage of forms, proper submission of forms,reporting and replenishing of stocks usingobservation and checklist. The daily entry of all malaria cases seen, diagnosed and treated using an Artemisini- based combination therapy, appropriate summary of all cases seen in a months,date of sending out forms, time for reporting stock-outs and time it took LGA to replenish stock out were checked at the health facility level. At the LGA level, the time health facility monthly forms were received, appropriate entering of all collated forms from the health facilities, time LGA summary forms are sent to the state RBM programme and time for reporting stock-out of malaria commodities received from the facilities and replenishing them were cross examined using the observation checklist as well. The researchers also collected information on health workers/officer knowledge, attitude and perception on monitoring and evaluation of malaria control activities as well as their general practice on malaria activities using a pre-tested interviewer administered questionnaire.

\subsubsection{Data Collection}

At the baseline, Socio-demographic characteristic of the study population, health workers' knowledge of malaria control strategies implemented for the past one year in the state, level of stock-out of commodities and the various means in which stock-out of commodities were communicated to the next higher level in the past one month were assessed using a structured questionnaire prepared in English language. Health workers/officer who 
mentioned at least one malaria control strategy and sending out report or form on stock-out as a method of communicating stock-outs of malaria commodities were categorized as having good knowledge. Since there was no observation of reports or forms sent out, it was referred to perceived activity. However, observation was made in 21 local government areas and 210 selected health facilities to check for utilization of malaria control activities, forms used to send out stock-out of malaria commodities, use of $M \& E$ forms and duration of sending out $M \& E$ forms, stock-out forms and receiving stocks of malaria commodities.

\subsection{Data Analysis}

The data was pooled across the 210 surveyed health facilities and was analyzed using statistical package for social science version 15 (SPSS 15). The different health facilities were coded and the coding was used in the questionnaire for identification. Each of the coding was entered into the computer during data entry. Data entry was done by trained data entry clerks and was double entered to ensure that no data was missed out in the data entry process All the entered data were double checked by researchers and principal investigators who are malaria experts.

Frequencies were calculated for malaria intervention implemented in the past one year to determine the level of intervention. Frequencies were also calculated for stock out of malaria commodities in the past one month. Mean and standard deviation were used to calculate the frequency in reporting and replenishing stock-outs of malaria commodities. The relationship between the various training held on the use of M\&E tools, frequency and timeline for reporting and replenishing stock-out were determined using cross tabulation.Cross tabulation was also used to relate the relationship between reporting of stock-outs and the different cadres of health workers.

Chi square test which was based on p-level of 0.5 were used for test to significance for variables on relationship between frequency of reporting stock-out and cadres of health worker.

\subsection{Ethical Clearance}

Ethical approval was obtained from the Ethics committee of the University of Nigeria Teaching Hospital, Enugu. Enugu state Nigeria.Written informed consent was obtained from each health worker in the selected health facility.

\section{Results and Discussions}

Data was collected across 210 health workers in 210 health facilities but, the number of completed questionnaire that were available for analysis was 207 , giving a response rate of $98.6 \%$. Most of the respondents were heads of facilities. Table 1 shows that there were 57 Nurse/ Midwives and 52 community-health extension workers (CHEW). Majority (95.3\%) of the respondents interviewed were females and CHEWS (40.9\%)A large number of respondents $(20.5 \%)$ were trained on the use of M\&E tools. Few $10(4.7 \%)$ were trained by Society for Family Health (SFH) while majority $44(20.9 \%)$ of the respondents were trained by the Health Policy Research Group (HPRG), University of Nigeria. A small number of the respondents were trained by other projects.

Table 1. General characteristics of the health workers

\begin{tabular}{|c|c|}
\hline General characteristics & $\begin{array}{l}\mathrm{N}=215 \\
\text { Frequency }(\%)\end{array}$ \\
\hline \multicolumn{2}{|l|}{ Official designation: } \\
\hline Malaria control program & $26(12.1)$ \\
\hline Nurse/Midwife & $57(26.5)$ \\
\hline M\&E /DSNO & $4(1.9)$ \\
\hline Head of facility/ director/HOD & $71(33.0)$ \\
\hline JCHEW/SCHEW/CHO & $52(24.2)$ \\
\hline Others & $5(2.3)$ \\
\hline Health assistant & 4 \\
\hline T.B officer & 1 \\
\hline \multicolumn{2}{|l|}{ Sex: } \\
\hline Male & $10(4.7)$ \\
\hline Female & $205(95.3)$ \\
\hline \multicolumn{2}{|l|}{ Age } \\
\hline Mean(S: D) & $40.49(10.27)$ \\
\hline \multicolumn{2}{|l|}{ Cadre: } \\
\hline Chew & $86(40.9)$ \\
\hline Nurse & $15(7.0)$ \\
\hline Midwife & $8(3.7)$ \\
\hline Nurse/midwife & $82(38.1)$ \\
\hline Environmental Health officer & $10(4.7)$ \\
\hline Doctors & $1(0.5)$ \\
\hline
\end{tabular}

\subsection{Malaria Control Intervention Implemented in the Past One Year}

Table 2. laria control intervention implemented in the past one year (according to the health workers)

\begin{tabular}{lc}
\hline Malaria control intervention implemented & No (\%) \\
\hline Indoor residual spray & $12(6.1)$ \\
Insecticide treated nets & $165(83.3)$ \\
Artemisinin- based combination therapy & $192(97.0)$ \\
Intermittent-preventive treatment for malaria in & $179(90.4)$ \\
pregnancy & $10(5.1)$ \\
Rapid diagnostic test & $5(2.5)$ \\
\hline
\end{tabular}

As shown in Table 2, the major malaria control interventions that the respondents stated or knew that were implemented in the past one year in the state were deployment of ACT 207(96.3\%), Intermittent-Preventive Treatment (IPT) 212 (89.3\%), Long Lasting Insecticide treated Net (LLIN) 179 (83.3\%). Indoor residual spraying 
$12(5.6 \%)$ and Rapid Diagnostic Test (RDT) were barely 11 $(5.1 \%)$ implemented as a malaria control intervention in the state.

\subsection{Occurrence of Stock-Out of Malaria Commodities in the Past one Month}

Table 3. ock-out of malaria commodities in the past one month

\begin{tabular}{ll}
\hline Stock-out of Commodities in the past one month & No (\%) \\
\hline Stock out of ACTs & $107(54.0)$ \\
Stock-out of RDTs & $119(60.1)$ \\
Stock-out of LLIN & $69(34.8)$ \\
Stock out of SPs & $37(18.7)$ \\
\hline
\end{tabular}

The most common malaria commodity that was reported to be out-of-stock was RDT (Figure 2). The incidence was reported by $126(58.6 \%)$ respondents.Most of the health facilities had a high $117(54.4 \%)$ stock-out of ACTs as shown in table 3

\subsection{Frequency and Timeline for Reporting and Replenishing Stock-Outs}

Table 4 shows that it takes a longer time of mean (8.5) before $M \& E$ forms are sent from the health facility or LGA to a higher level. Also, it takes many days (7.3) after stockout of LLIN before reporting to the next higher level. It equally takes a long number of days (5.3) after stock-out of ACT before information is reported to the next higher level. However, few (2.1) days elapsed after stock-out of M\&E forms before the information on stock-outs is sent to the next level. The disaggregation of training on M\&E by different organizations and stock-outs is shown in Table 3

Table 4. equency and timeline for reporting and replenishing stock-outs

\begin{tabular}{l} 
Frequency and timeline \\
No of times M\&E forms are sent from HF/LGA to higher level \\
No of days elapsed after stock-out of ACTsbefore information is sent to the next level \\
No of days elapsed after stock-out of SP before information is sent to the next level \\
No of days elapsed after stock-out of RDTs before information is sent to the next level \\
No of days elapsed after stock-out of LLINs before information is sent to the next level \\
No of days elapsed after stock-out of M\&E forms before information is sent to the next level \\
\hline
\end{tabular}

Table 4. lationship between Frequency of reporting of stock-out and cadres of health workers

\begin{tabular}{|c|c|c|c|c|c|c|c|c|c|}
\hline $\begin{array}{l}\text { Frequency for reporting stock- } \\
\text { outs }\end{array}$ & $\begin{array}{c}\text { CHEW } \\
\mathbf{N}=86\end{array}$ & $\begin{array}{l}\text { Nurse } \\
\mathrm{N}=15\end{array}$ & $\begin{array}{l}\text { Midwife } \\
\mathrm{N}=\mathbf{8}\end{array}$ & $\begin{array}{l}\text { Nurse-Midwife } \\
\qquad \mathbf{N}=\mathbf{8 2}\end{array}$ & $\begin{array}{l}\text { Environmental health } \\
\text { Officer } \\
\mathbf{N}=10\end{array}$ & $\begin{array}{c}\text { Doctor } \\
\mathrm{N}=1\end{array}$ & $\begin{array}{l}\text { Others } \\
\mathbf{N}=\mathbf{3 9}\end{array}$ & $X^{2}$ & P-value \\
\hline $\begin{array}{l}\text { No of times M\&E forms are sent } \\
\text { from HF/LGA to higher level. } \\
1-10 \text { days }\end{array}$ & 36 & 8 & 5 & 18 & 2 & 1 & 13 & 1.573 & 0.210 \\
\hline$>11$ days & 38 & 5 & 3 & 53 & 7 & 0 & 23 & 1.599 & 0.206 \\
\hline $\begin{array}{l}\text { No of days elapsed after stock- } \\
\text { out of ACTsbefore information is } \\
\text { sent to the next level. } \\
1-10 \text { days }\end{array}$ & 28 & 6 & 3 & 28 & 4 & 0 & 14 & 0.101 & 0.751 \\
\hline$>11$ days & 9 & 3 & 1 & 8 & 1 & 0 & 3 & 0.122 & 0.727 \\
\hline $\begin{array}{l}\text { No of days elapsed after stock- } \\
\text { out of SP before information is } \\
\text { sent to the next level. } \\
1-10 \text { days }\end{array}$ & 16 & 6 & 1 & 20 & 3 & 0 & 11 & 0.899 & 0.343 \\
\hline$>11$ days & 5 & 2 & 1 & 5 & 2 & 0 & 2 & 0.070 & 0.791 \\
\hline $\begin{array}{l}\text { No of days elapsed after stock- } \\
\text { out of RDTs before information } \\
\text { is sent to the next level } \\
1-10 \text { days }\end{array}$ & 4 & 0 & 0 & 6 & 1 & 0 & 4 & 1.756 & 0.185 \\
\hline$>11$ days & 2 & 0 & 0 & 4 & 0 & 0 & 2 & 0.045 & 0.832 \\
\hline
\end{tabular}




\begin{tabular}{|c|c|c|c|c|c|c|c|c|c|}
\hline $\begin{array}{l}\text { Frequency for reporting stock- } \\
\text { outs }\end{array}$ & $\begin{array}{c}\text { CHEW } \\
\mathbf{N}=86\end{array}$ & $\begin{array}{l}\text { Nurse } \\
\mathrm{N}=15\end{array}$ & $\begin{array}{l}\text { Midwife } \\
\mathbf{N}=\mathbf{8}\end{array}$ & $\begin{array}{c}\text { Nurse-Midwife } \\
\quad \mathbf{N}=82\end{array}$ & $\begin{array}{c}\text { Environmental health } \\
\text { Officer } \\
\mathrm{N}=10\end{array}$ & $\begin{array}{c}\text { Doctor } \\
\mathrm{N}=1\end{array}$ & $\begin{array}{l}\text { Others } \\
\mathbf{N}=39\end{array}$ & $\mathbf{X}^{2}$ & P-value \\
\hline $\begin{array}{l}\text { No of days elapsed after stock- } \\
\text { out of LLINs before information } \\
\text { is sent to the next level. } \\
1-10 \text { days }\end{array}$ & 14 & 3 & 1 & 15 & 2 & 0 & 8 & 0.378 & 0.539 \\
\hline$>11$ days & 4 & 2 & 1 & 6 & 1 & 0 & 2 & 0.175 & 0.676 \\
\hline $\begin{array}{l}\text { No of days elapsed after stock- } \\
\text { out of M\&E forms before } \\
\text { information is sent to the next } \\
\text { level. }\end{array}$ & 7 & 1 & 1 & 11 & 2 & 0 & 5 & 1.463 & 0.226 \\
\hline $\begin{array}{l}1-10 \text { days } \\
>11 \text { days }\end{array}$ & 2 & 0 & 0 & 3 & 1 & 0 & 2 & 1.110 & 0.292 \\
\hline
\end{tabular}

\subsection{Relationship between Frequency for Reporting Stock-Outs and Cadres of Health Workers}

Table 5 shows that it took a longer number of times for reporting stock-out of all malaria control commodities to a higher level by Nurse-midwives. CHEW also reported stock-out of malaria commodities at different times and there was no statistical difference between frequency for reporting stock-out and cadres ( $p$-value $>0.05$ ).

Table 5. equency and timeline for reporting and replenishing stock with the different Trainings held on M\&E of malaria control activities.

\begin{tabular}{|c|c|c|c|c|}
\hline Frequency and timeline & $\begin{array}{l}\text { SFH only } \\
\quad \mathrm{N}=7\end{array}$ & $\begin{array}{l}\text { HPRG only } \\
\qquad \mathbf{N}=39\end{array}$ & $\begin{array}{l}\text { SFH \&HPRG } \\
\quad \mathbf{N}=\mathbf{4 0}\end{array}$ & $\begin{array}{l}\text { OTHERS } \\
\mathbf{N}=\mathbf{3}\end{array}$ \\
\hline No of times M\&E forms are sent from HF/LGA to higher level & 0 & 2 & 1 & 1 \\
\hline No of days elapsed after stock-out of ACTsbefore information is sent to the next level & 4 & 6 & 8 & 0 \\
\hline No of days elapsed after stock-out of SP before information is sent to the next level & 4 & 7 & 7 & 0 \\
\hline No of days elapsed after stock-out of LLINs before information is sent to the next level & 0 & 3 & 3 & 0 \\
\hline $\begin{array}{l}\text { No of days elapsed after stock-out of } M \& E \text { forms before information is sent to the next } \\
\text { level }\end{array}$ & 0 & 1 & 2 & 0 \\
\hline
\end{tabular}

\section{Discussions}

As found in this study and by other studies,stock-out of rapid diagnostic testing (RDT) and in-door residual spraying (IRS) interventions were barely reported in public health facilities.[15] These results at public health facilities are extremely concerning and are related to unavailability of preventive measures, training programmes andapproaches/interventions.[16]

There were frequent records on occurrence of stock outs of malaria commodities. The occurrence of stock-outs on RDT and ACT was found to be very high compared to the results of a study in which it was reported to have stock out of ACTs in health facilities. [17,18] . The higher level of stock-outs of ACT in health facilities at the time of the survey is likely to be due to reporting, communication and procurement delays that massively compromised ACT replenishment in Nigeria. The investigation on the causes of stock-out of ACTs is beyond M\&E and studies investigating reporting and procurement chain are necessary to understand the problem. Some studies suggested that stock-outs of ACTs are also as a result of irrational use of ACTs due to low testing, even when tested and result showed negative result in clinical practice. $[19,20]$

Effective training, supervision, communication and reporting are necessary to improve monitoring and evaluation in malaria control. Besides the training held for selected health workers on the use of monitoring and evaluation tools in this study, it was observed that it took a longer time before information on stock-out are communicated to the next level and replenished. It was difficult for other health workers not trained to appreciate the importance of timely reporting and communication at the next level This is consistent with a study done in Anambra state on knowledge of DSN where head of facilities have attended several workshops but no in-service or step down training were offered to other health workers to appreciate the role they are expected to perform in disease reporting. [10] Untimely supply of stock-outs was also reported in a survey conducted in Kenya in which stock-out of anti malarial are not supplied timely. These stock-outs were related to the use of inappropriate channel of communicating stock-outs [21], inadequate ordering, distribution and supply of malaria commodities. [22] For example, it was found that training was a strategy used to 
increase knowledge and attitude of health workers in communicating stock-outs.

The findings show that most stock-outs were reported by the lower cadres of health workers. The lower level cadre consist mostly the junior and senior CHEW trained to provide a safe and quality primary health care delivery under doctor's supervision. [23-26] However, there are no evidence from other studies on relationship between cadre of health workers and reporting stock-out of malaria commodities at higher level. It should be noted that these cadres were defined at primary health care facility level and it is not possible to link reporting of stock-outs to a cadre of health worker that reported it either because the health worker was off duty at the time of the survey or because several health workers may have reported stock-out at various times within the month of stock-out of malaria commodities.

All in all, monitoring and evaluation of malaria control has been a part of strategic intervention for malaria control programme in Nigeria since 2007.[7] It also serves as an integral part of NHIMS. Although, interventions to improve M\&E in malaria control are poorly implemented, less than a quarter of the health workers in health care facilities have been trained on the use of M\&E tools for malaria control.However, there's increasing emphasis on improving $M \& E$ in malaria control, the study suggests that there's need for strategies that also improve use of M\&E tools for malaria control.

\section{Conclusion}

Improving the use of M\&E tools should also address effective reporting method, and ensure that an effective strategy is designed and implemented to ensure that health workers can communicate stock-outs of malaria commodities to higher level. Concurrently, attention needs to be given to the timeline as well as frequency in replenishing stock-outs of malaria control. Considerations should be given to intermittent training, re-training, supportive supervision and use of rapid SMS as part of strategies that could be used to improve the use of $M \& E$ tools for malaria control. The findings of this study are useful for policy makers and program managers in developing interventions that will proffer solutions to optimize procurement and supply chain management system timely to avoid forecasting as well as to provide real time feedback to National malaria control program at the LGA, state and federal level on flow of interventions.

\section{Authors' Contributions}

All authors contributed to this work. OO, BSCU, JO and ALI conceived and designed the study. All the authors participated in data collection and analysis.JCE drafted the manuscript with input from all the authors. All authors approved the final draft of the paper.

\section{References}

[1] Federal Ministry of Health. National framework for monitoring and evaluation of malaria control in Nigeria.2007 Available at http://nmcpnigeria.org. Date assessed (15/03/11)

[2] Federal Ministry of Health. Monitoring and evaluation plan for malaria control in Nigeria. 2009. Available athttp://www.pdfchaser.com/pdf/national-malaria-controlprogramme-in-nigeria.html.Date assessed (30/12/10)

[3] Federal Ministry of Health. Training module on monitoring and evaluation of national malaria control programme in Nigeria for state and LGA health workers. Available at http://www.pdfchaser.com/pdf/national-malaria-controlprogramme-in-nigeria.html. Date assessed (30/12/10)

[4] Uzochukwu B, Ezeoke Ogochukwu, Emma-Ukaegbu U and Onwujekwe $O$ et al. Malaria treatment services in Nigeria. Nigerian Medical Journal. 2010;51(3):144-119. Available at http://www.nigeriamedj.com. Date assessed (14/02/11)

[5] Shiff C. Intergrated approach to malaria control. Clinical Microbiology review, American society of microbiology. 2002;15(2):278-293. Available at http://cmr.asm.org/cgi/content/full/15/2/278.Date assessed $(15 / 03 / 11)$

[6] MEASURE Evaluation. Annual Monitoring of Health Outcome Indicators. Chapel Hill: MEASURE Evaluation; 2006.

[7] National M\&E framework (2007). Federal Ministry of Health. National framework for monitoring and evaluation of malaria control in Nigeria. 2007Available at www.nmcpnigeria.org

[8] Federal ministry of health. National malaria control programme: revised 5-year strategic plan, 2006-2010)

[9] World Health Organization. Nigerian malaria control booster project: project report of the malaria control booster project. 2008-2010. Available at http://nmcpnigeria.org/?p=nmcbp. Date assessed (5/01/11)

[10] Nnebue C, Onwsigwe C, Adogu P, Onyeonoro U. Awareness and knowledge of disease surveillance and notification by health care workers and availability of facility records in Anambra state, Nigeria. Nigeria Medical Journal. 2012;53:220-5

[11] Federal Ministry of Health. Monitoring and evaluation for malaria control in Nigeria 2009

[12] Oyegbite KS. Health data in Nigeria; review of existing situation, form and format. Abuja, Nigeria: Proceedings of the conference on National Health Management Information System; 1992. p. 42-4

[13] Mbachu C, Onwujekwe O, Uzochukwu BSC, Uchegbu E and Oranuba $\mathrm{J}$ et al $>$ Examining equity in access to longlasting insecticide nets and Artemisinin-based combination therapy in Anambra state, Nigeria. BMC Public Health. 2012;12:315

[14] Anambra state of Nigeria. State Economic Empowerment and Development Strategy (SEEDS). $2^{\text {nd }}$ edition. Awka;2007Unpublished ministry of health 
[15] Carneiro P, Locatelli A, Ghebremeskel T and Keating J. Do public health interventions crowd out private health investments? Malaria control policies in Eritrea.Eritrea Ministry of health. 2011. Available at www. econ.yale.edu

[16] Kokwaro G. Ongoing challenges in the management of malaria. Malaria Journal. 2009:8;1: doi:10.1186/1475-28758-S1-S2. Available $\mathrm{http}: / /$ www.malariajournal.com/content/8/S1/S2.

[17] Sudoi R, Githinji, Nyandigisi A, Snow R, Zurovac. The magnitude and trend of artemether-lumefantrine stock-outs at public health facilities in Kenya. Malaria Journal 2012;11:37 doi:10.1186/1475-2875-11-37. Available at http://www.malariajournal.com/content/11/1/37

[18] Batwala V, magnussen $P$ and Nuwaha F. Challenges to implementation of Artemisinin combination policy in Uganda. International health journal. 2010;2(4):262-268. Available http://www.internationalhealthjournal.com/article/S1876 3413(10)00046-X/abstract. Date assessed (15/02/11)

[19] Juma E, Zurovac D: Changes in health workers' malaria diagnosis and treatment practices in Kenya. Malaria journal 2010, 10:1
[20] Hamer DH, Ndhlovu M, Zurovac D, Fox M, Yeboah-Antwi $\mathrm{K}$, et al. (2007) Improved diagnostic testing and malaria treatment practices in Zambia. JAMA 297: 2227-2231.

[21] Nyandigisi A, Memusi D, Mbithi A, Ang'wa N, Shieshia M, Muturi A, Sudoi RK, Githinji S, Juma A, Zurovac D: Malaria case-management following change of policy to

[22] WorldHealthOrganization. Tanzania pilot project report: SMS for life. 2010

[23] Kangwana BB, Njogu J, Wasunna B, Kedenge SV, Memusi DN, et al. (2009) Malaria drug shortages in Kenya: A major failure to provide access to effective treatment. Am J Trop Med Hyg 80: 737-738.,16,17

[24] Zurovac D, Ndhlovu M, Sipilanyambe N, Chanda P, Hamer $\mathrm{DH}$, et al. (2007) Paediatric malaria case-management with artemether-lumefantrine in Zambia: a repeat cross-sectional study. Malar J 6: 31. Find this article online

[25] Zurovac D, Tibenderana JK, Nankabirwa J, Ssekitooleko J, Njogu JN, et al. (2008) Malaria case-management under artemether-lumefantrine treatment policy in Uganda. Malar J 7: 181

[26] Viedder M, Friedman J, Sjoblom M, and Yadav P. Enhancing public supply chainmanagement in Zambia 